\title{
An Integrated Boost-Sepic Higher Static Gain DC-DC Converter for Photovoltaic (PV) Based Micro-Grid Application
}

\author{
*H. Isah, Y. M. Sagagi and Y. Aliyu \\ Department of Physics/Electronics, Federal University, Birnin Kebbi \\ [Corresponding Author: huzaifa.isah@fubk.edu.ng]
}

\section{ABSTRACT}

A new circuit topology is designed for a DC-DC converter. The proposed converter employs a single power switch which integrates a conventional boost with a single-ended primary inductor converter (SEPIC) for photovoltaic (PV) panels. A prototype is developed and implemented for $105 \mathrm{~V}$ DC output from $9 \mathrm{~V} \mathrm{DC}$ input. The performance of the proposed topology was validated using theoretical and practical verification. The results indicated a higher voltage gain of 11.67, low duty-cycle of 0.82 and reduced voltage stress across the components of about $54 \mathrm{~V}$. The circuit can be used for PV panels and other renewable energy resources that require a DC-DC voltage step-up conversion ratio.

Keywords: DC-DC step-up Converter, Photovoltaic (PV) panel, Voltage gain, Duty-cycle and Voltage stress.

\section{INTRODUCTION}

Carbon-neutral society can be achieved by switching from fossil fuels to renewable energy power resources (Isah et al., 2019). This energy transformation is capable of enhancing the economy, bring resilience to disasters and help the rural communities to access electricity with less compromisation to their environments (Isahet al., 2020). Solar power is one of the naturally available, clean and cheap energy resources that require the use of photovoltaic (PV) panels for electricity generation (Gopi and Sreejith, 2018; Engin and Çak, 2016).

PV panels harness the sun in the form of electromechanical energy and convert it into electrical energy through the use of solar cells (Oulad-abbou et al., 2019; Ahmad et al., 2019; Jiang et al., 2016). Weather conditions and areas for installations are some of the significant factors affecting the performances of PV panels (Kuo et al., 2015). PV system of electricity generation can either be for grid connection or micro-grid connection (Kuo et al., 2015; Öztürk et al., 2018).Usually, the grid connection requires utility substations. For that reason, a lot of PV panels are required to construct solar farmland, which in turn occupy an extensive area meant for agricultural practices and other purposes, whereas micro-grid or sometimes called off-grid system is for domestic and industrial purposes which can be installed on the rooftops and can easily be affected by the shadow of trees and tall buildings. PV panels are naturally known to generate a low voltage in nature, which is not sufficient for energy storage or inverter applications (Kumar et al., 2017). This means there is an increasing demand for energy every day, and voltage per PV generating unit is proportionally low (Engin and Çak, 2016). Hence, there is a need for adaptation of power converter technology.

A power converter can be used to step-up low dc voltage generated by the PV panel into a desired output dc voltage value. There are two types of the power converter, they are; DC-DC and DCAC (H-ossain and Rahim, 2018). The former can be placed at the back of the individual PV panel or anywhere in between the panel and storage device to act as an impedance unit to the PV panel. The latter could serve as an inverter connected between the storage device and grid lines. The DC-DC converters are subdivided into isolated and non-isolated (Amir et al., 2018). The isolated converters require the use of a transformer, examples are; fly-back, push-pull among many others (Fathabadi, 2016). Fly-back 
is the most widely used and its topology is well exploited in the literature due to its simplicity and higher power efficiency (Fernão et al., 2017; Imamet al., 2019). Also, it has a mode of operation with other non-isolated buck-boost converters, but its disadvantage is higher voltage gain depend on the duty-cycle and turn ratio of the transformer(Gopi and Sreejith, 2018). Nonisolated converters don't require transformer and higher voltage gain depend on duty-cycle only. Examples of transformer-less non-isolated DCDC converters are; Boost Converters, Interleaved, Switch Capacitor with Switch Inductor among many others.

There are many types of boost converters with some of their topologies already exploited in the literature and were realized by either utilizing switch capacitor, integrating two or three converters or incorporating them with voltage multiplier cells (Ajami et al., 2015; Kumar et al., 2017; Saravanan and Babu, 2017; Rizky et al., 2018). Comparatively, low voltage gain, higher duty-cycle and higher switching stress across the semiconductor devices have been the problems of every presented converter (Fernão et al., 2017; Saravanan and Babu, 2017; Sabzali et al., 2014). The conventional boost converters can achieve a higher voltage gain at the expense of a higher duty-cycle which can cause complexity within the semiconductor components (Gopi and Sreejith, 2018; Engin and Çak, 2016). The single-ended primary inductor converter (SEPIC) can achieve a moderately low duty-cycle with low voltage stress across its components but the voltage gain is believed to always be low (Ouladabbou et al., 2019; Ahmad et al., 2019).The switch capacitor with switch inductor converters can achieve a higher gain with a low duty-cycle but the stress across the semiconductor is believe to be too much (Tewari and Sreedevi, 2018; Axelrod et al., 2003). Cuk is too expensive and besides, it has higher stress across the active components (Taghvaee et al., 2013). This means that, it is hard to design a converter with high voltage gain, low duty-cycle and less stress across the semiconductor components, it had to suffer at least one of the three mentioned factors (Navamani et al., 2016).

There are lots of works presented by many researchers to solve the aforementioned problems. Some topologies utilize voltage multiplier cell Saravanan and Babu, (2017), switch capacitor Ajami et al., (2015) while others utilize two or three converters being integrated (Pires., 2016; Kumar et al., 2017).The double boost integrated with a single-ended primary inductor (SEPIC) converter proposed in Sabzali et al., (2014) has a higher voltage gain with a relatively good duty-cycle, but the stress across the components was believed to be too much for the converter. The DC-DC converter reported in Pires et al., (2016)by joining boost with self-lift Cuk has a moderate duty-cycle value with relatively low voltage gain. A boost-boost combination in Ching-ming et al., (2017) has a reasonable duty-cycle value. However, the voltage gain value is low. A triple combination consisting of Boost-SEPIC integrated with Cuk reported in Kumar et al. (2017) has a good value of voltage gain with a low duty-cycle. However, the voltage stress across the components deemed too high.

This paper presents a single switch DC-DC stepup converter built by adding some components of single-ended primary inductor converter (SEPIC) to the conventional boost converter (boostSEPIC) for PV and other renewable applications. The proposed topology utilizes one power switch with increased voltage gain and low voltage stress within the semiconductor components. This topology will take $9 \mathrm{~V} \mathrm{DC}$ voltage as input and generate $105 \mathrm{~V} D C$ as output.

\section{MATERIALS AND METHODS Materials}

The new converter was built with two inductors $\left(L_{1} \& L_{2}\right)$, two diodes $\left(D_{1} \& D_{0}\right)$, three capacitors $\left(C_{1}, C_{2} \& C_{0}\right)$, one power switch (Sw),a load resistor $\left(R_{L}\right), D x 9$ socket and pulse generator. Components are considered ideal because they were selected from the datasheet. The 
components were purchased at MICA electronics Ltd, Kano. Nigeria.

\section{Methodology}

The proposed circuit in Figure 1 was constructed by integrating a conventional boost with a SEPIC converter. In modification to the method adopted by Kumar et al., (2017), the Cuk converter there has now been removed to make the new topology cheap and the negative terminal of $C_{2}$ has now been placed between the $L_{2}$ and $D_{0}$ which extend the voltage gain of the present study. This method also altered the one presented in Saravanan and Babu, (2017) hereby substituting the voltage doubler used there with a conventional boost converter. After the realization of the circuit, Multism version 11.0.1 was used to run the simulation of the proposed topology. After that, a Trainer (TPS 3371) was employed to validate the output of the proposed converter in the laboratory.

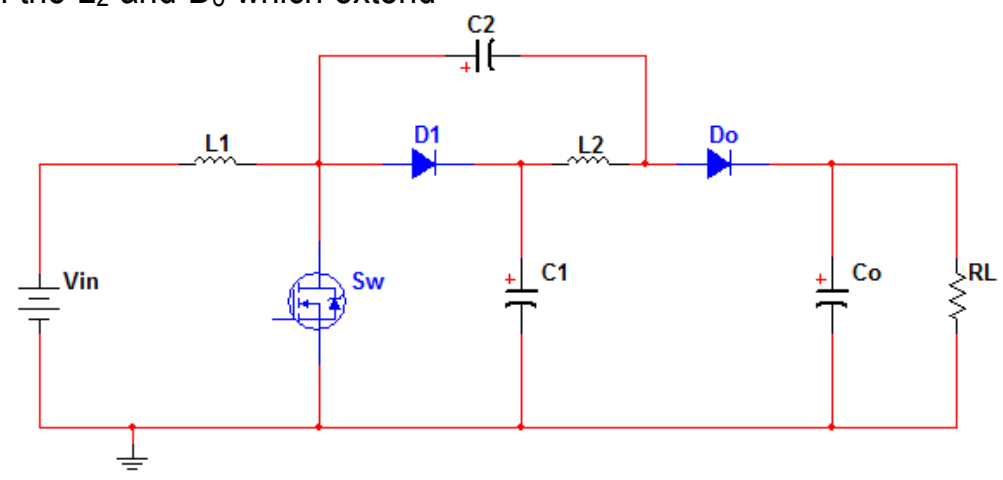

Figure: 1: Proposed topology.

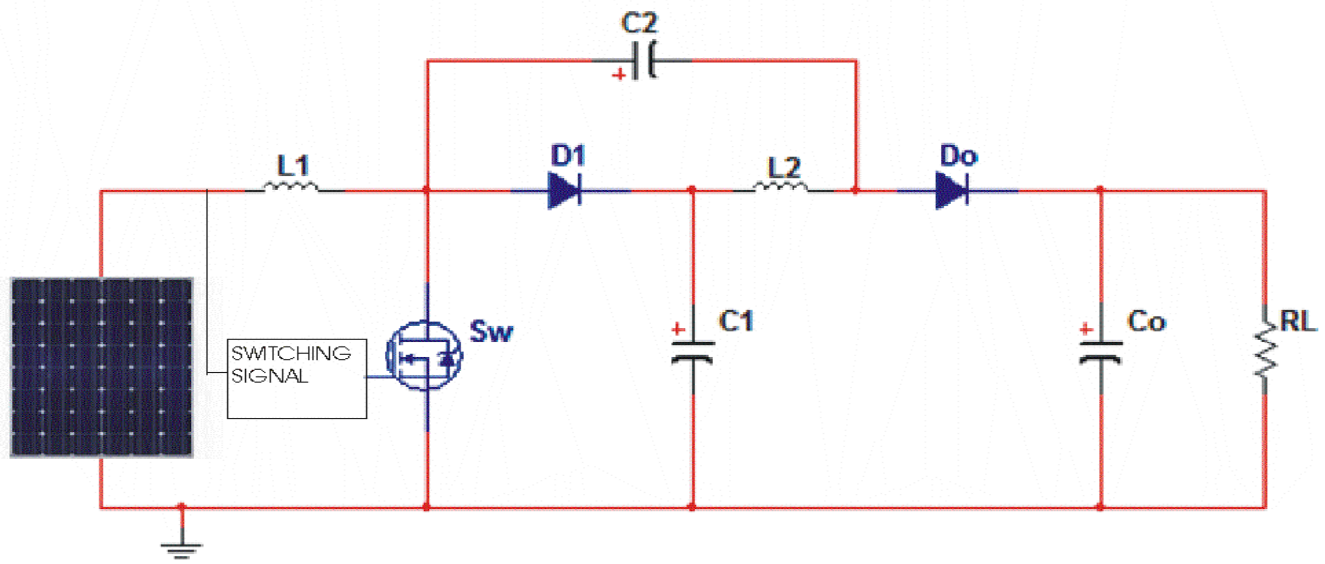

Figure 2: Proposed topology with the PV panel.

\section{Operation Principle of the Proposed Topology under Continuous Conduction Mode:}

\section{Stage 1:}

When switch $S_{w i s}$ turned $O N$, inductors $L_{1} \& L_{2}$ stores energy and their current will increase linearly. Diode $D_{1}$ will charge capacitor $C_{1}$ while diode $D_{0}$ will be reverse bias. Capacitor $C_{2}$ will receive energy from the switch and capacitor $\mathrm{C}_{0}$ will discharge to the output.

\section{Stage 2:}

When switch $S_{w}$ is turned OFF, inductors $L_{1} \&$ $L_{2}$ will discharge energy and their current will decrease linearly. Diode $D_{1}$ will be reverse bias and diode $D_{0}$ will deliver energy to the capacitor Co. 


\section{THEORETICAL ANALYSIS}

The theoretical analysis of a conventional boost converter can be written as viz:

$V_{i} \partial T=\left(V_{o}-V_{i}\right)(1-\partial) T \quad$ (Rashid., 2001) (1)

$V_{i} \partial T=\left(V_{C_{O}}-V_{i}\right)(T-\partial T)$

The theoretical analysis of the present study can be computed using Figure 1,

$V_{\text {in }}=V_{L 1}$

$V_{s w}=V_{C 1}=V_{C 2}=V_{L 2}$

Where: $V_{\text {in }}=$ input voltage $; V_{L 1}=$ voltage across $\mathrm{L}_{1} ; V_{S w}=$ voltage across the switch; $V_{C 1}=$ voltage across $\mathrm{C}_{1} ; V_{C 2}=$ voltage across $\mathrm{C}_{2}, V_{L 2}=$ voltage across $L_{2}$;

The average current passing through inductor $L_{1}$ can be computed as viz;

$\Delta I_{1}=\frac{V_{i n} \partial}{f L_{1}} \quad($ Saravanan and Babu, 2017) (5)

The current passing through inductor $L_{2}$ can be computed as;

$\Delta I_{2}=\frac{V_{C 1}(1-\partial)}{f L_{2}}$

Though, $C_{O}$ represents the capacitor for the SEPIC converter but the voltage it contains is a sum of the boost and SEPIC combined. That is;

$V_{C O}=V_{C 1}+V_{C 2}$

From equation (3), it means that $V_{C 1}$ is the output voltage of the boost converter and $V_{C 2}$ is the output voltage of the SEPIC converter. The sameequation (3) can be rewritten as:

$V_{B S}=V_{B}+V_{S}$
Where $\quad V_{B S}=V_{C O}$.And $V_{B S}$ means output voltage of the boost and SEPIC converters combined.

Normally, the input/output relationship of the boost converter can be written as:

$V_{B}=\left(\frac{1}{1-\partial}\right) V_{\text {in }}$ as reported in (Kumar et al., 2017) (9)

$\partial$ represents duty-cycle.

Thus, equation (7) can be written in terms of the voltage gain of the SEPIC converter as:

$g_{S}=\frac{V_{S}}{V_{\text {in }}}=\left(\frac{\partial}{1-\partial}\right)$

$g_{B}$ and $g_{s}$ mean voltage gain of the boost and SEPIC converters

Therefore, combining equation (6) \& (8) will give the voltage gain of the new converter as;

$g_{B S}=g_{B}+g_{S}$

That is; $g_{B S}=\frac{V_{B S}}{V_{\text {in }}}=\frac{1+\partial}{1-\partial}$

From equation (10),the duty-cycle of the new converter can be evaluated as:

$\partial=\frac{V_{B S}-V_{i n}}{V_{B S}+V_{i n}}$

From equation (10) again, the voltage across the output capacitor can be written as:

$V_{B S}=\left(\frac{1+\partial}{1-\partial}\right) V_{\text {in }}$ 
Isah et al. An Integrated Boost-Sepic Higher Static Gain DC-DC Converter for Photovoltaic (PV)

\section{RESULTS}

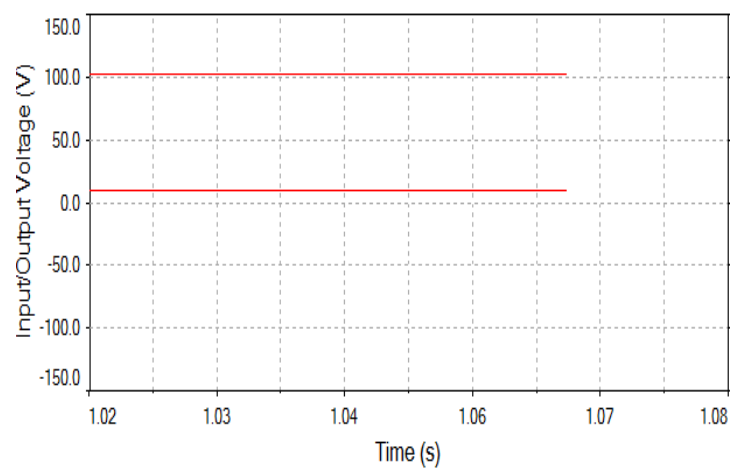

Figure 3: Input and output voltage signals.

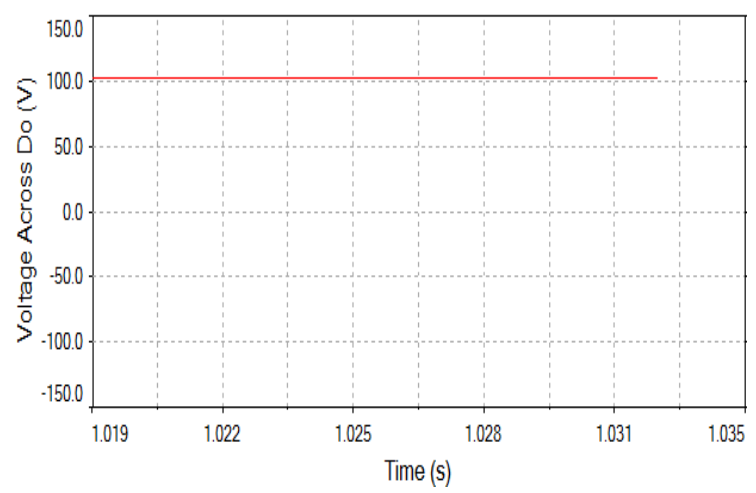

Figure 4: Voltage across the output diode.

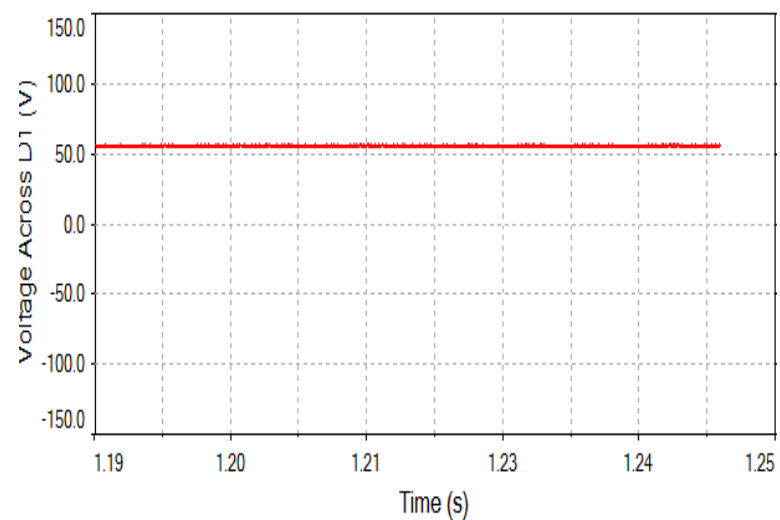

Figure 5: Voltage across diode $D_{1}$

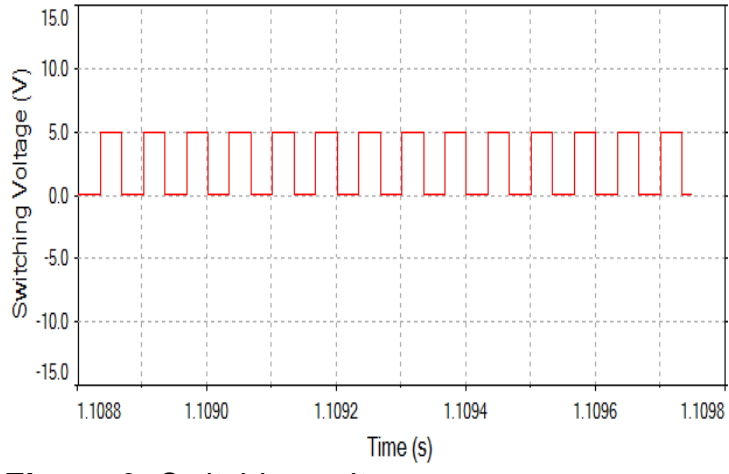

Figure 6: Switching voltage

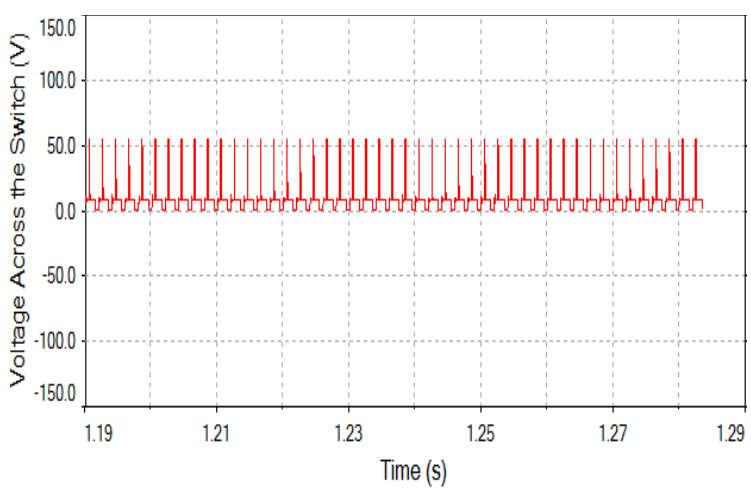

Figure 7: Voltage across the power switch

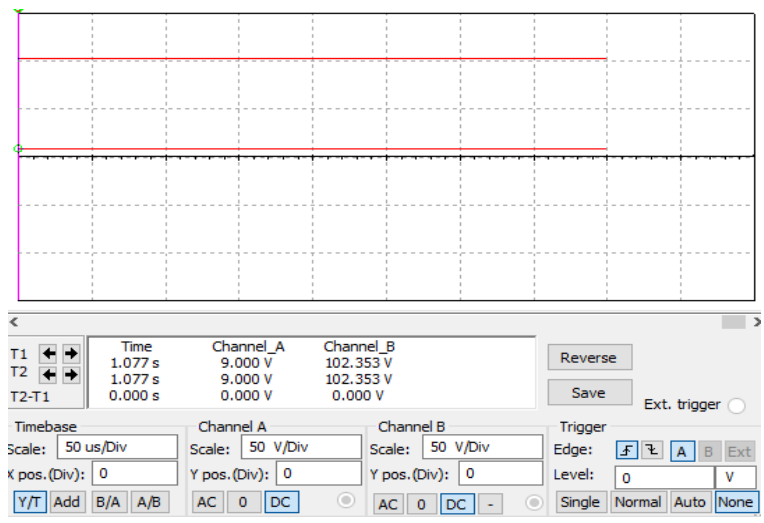

Figure 8: Input and output voltage obtained from oscilloscope using Dx9 socket. 


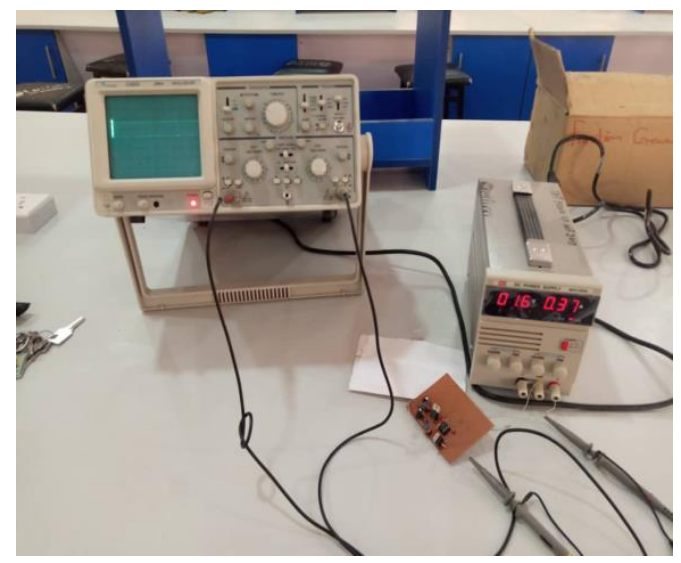

Figure 9: Experimental setup

Table 1: List of components and their values selected from Datasheet

\begin{tabular}{cc}
\hline COMPONENTS & VALUE \\
\hline $\mathrm{L}_{1}$ & $205 \mu \mathrm{H}$ \\
$\mathrm{L}_{2}$ & $1 \mathrm{mH}$ \\
$\mathrm{C}_{1}$ & $5 \mu \mathrm{F}$ \\
$\mathrm{C}_{2}$ & $10 \mu \mathrm{F}$ \\
$\mathrm{C}_{0}$ & $200 \mu \mathrm{F}$ \\
$\mathrm{D}_{1}=\mathrm{D}_{0}$ & $\mathrm{MUR} 115$ \\
Power Switch & IRFZ48 NS \\
\hline
\end{tabular}

Table 2: List of parameters and their values obtained from simulation

\begin{tabular}{cc}
\hline PARAMETER & VALUE \\
\hline Input Voltage & $9 \mathrm{~V}$ \\
Output Voltage & $105 \mathrm{~V}$ \\
Voltage Gain & 11.67 \\
Duty-cycle & 0.82 \\
Switching frequency & $30.3 \mathrm{KHz}$ \\
\hline
\end{tabular}

Table 3: List of parameters and their values obtained from experiment/theoretical equations

\begin{tabular}{cc}
\hline PARAMETER & VALUE \\
\hline Input Voltage & $9 \mathrm{~V}$ \\
Output Voltage & $102 \mathrm{~V}$ \\
Voltage Gain & 11.33 \\
Duty-cycle & 0.83 \\
Switching & $30.3 \mathrm{KHz}$ \\
frequency & \\
\hline
\end{tabular}

\section{DISCUSSION}

Simulation

Figure 3 represents the input/output signals obtained with a duty-cycle of 0.82 and it can be seen from the said figure that, $105 \mathrm{~V} \mathrm{DC}$ output was realized from $9 \mathrm{~V} D C$ input. This means a voltage gain of $g=11.67$ is confirmed, which is better than the values reported in (Saravanan and Babu, 2017; Pires et al., 2016; Kumar et al., 2017). For a free voltage stress converter, half of the output voltage value is expected to cross the active components. From Figures $5 \& 7$ it can be seen that $54 \mathrm{~V}$ DC voltage passed through diode $D_{1}$ \&active power switch $S w$ which is slightly above the expected values. This is proof that the voltage stress across the active components of the new converter has been minimized compared to the values reported in (Saravanan and Babu, 2017; Pires et al., 2016). Table 1 represents the list of components with their values while the values obtained from simulation are in Table 2. Figure 4 is the voltage across the output diode and Figure 6 represents the switching signal.

\section{Experimental/Theoretical}

To validate the simulated results, components in Figure (1) were placed on the trainer's (TPS 3371) PC board in the laboratory. Dx9 USB cable was connected between the trainer's socket and computer USB spot and signal in Figure 8 was generated from the screen. It can be seen from Figure (1) that $102 \mathrm{~V} \mathrm{DC}$ output voltage was obtained from $9 \mathrm{~V}$ DC input value and hence, a voltage gain of 11.33 is confirmed. But according to equation (14), the voltage gain value is 10.11 with a duty-cycle of 0.83 which is obtained from equation (15). These values of voltage gain and duty cycle improve the ones reported in Sabzali et al. (2014; Pires et al. (2016); Saravanan and Babu, (2017) and Kumar et al. (2017). The experimental set up is depicted in Figure 9 and values obtained after the experiment are in Table 3. 
Isah et al. An Integrated Boost-Sepic Higher Static Gain DC-DC Converter for Photovoltaic (PV)

\section{CONCLUSION}

A boost-SEPIC step-up DC-DC converter has been proposed in this paper. The results obtained shows that pairing boost and SEPIC converters together provide an extended voltage gain withthe reduced value of duty-cycle and the stress within the semiconductor components has been reduced to a minimum. This characteristic has makes the new converter ideal for application in PV panels and other renewable energy resources as shown in Figure 2.

\section{REFERENCES}

Ahmad, R., Murtaza, A. F., \& Ahmed, H. (2019). Power tracking techniques for efficient operation of photovoltaic array in solar applications - A review. Renewable and Sustainable Energy Reviews, 101: 82-102.

Ajami, A., Ardi, H., \& Farakhor, A. (2015). A Novel High Step-up DC/DC Converter Based on Integrating Coupled Inductor and Switched-Capacitor Techniques for Renewable Energy Applications. IEEE Transactions on Power Electronics, 30(8): 4255-4263.

Amir, A., Amir, A., Seng, H., El, A., \& Abd, N. (2018). Comparative Analysis of High Voltage Gain DC-DC Converter Topologies for Photovoltaic Systems. Renewable Energy, 18: 31163-31167.

Aprilianto, R. A., Semarang, U. N., Subiyanto, S., \& Semarang, U. N. (2018). Modified SEPIC Converter Performance for Grid-Connected PV Systems under Modified SEPIC Converter Performance for Grid-connected PV Systems under Various Conditions, 16: 2943-2953.

Axelrod, B., Berkovich, Y., \& loinovici, A. (2003). Voltage Multiplier Cells Applied to NonIsolated DC-DC Converters. Proceedings of the 2003 International Symposium on Circuits and Systems, 2003. ISCAS '03., 3(2), 871-887.

Engin, M., \& Çak, B. (2016). Comparisons of MPPT performances of isolated and nonisolated DC - DC converters by using a new approach. Renewable and Sustainable
Energy Reviews, 60: 1100-1113.

Fathabadi, H. (2016). Novel high efficiency DC / $\mathrm{DC}$ boost converter for using in photovoltaic systems. SOLAR ENERGY, 125: 22-31.

Fernão, V., Foito, D., \& Fernando, J. (2017). A single switch hybrid DC / DC converter with extended static gain for photovoltaic applications. Electric Power Systems Research, 146: 228-235.

Gopi, R. R., \& Sreejith, S. (2018). Converter topologies in photovoltaic applications - A review. Renewable and Sustainable Energy Reviews, 94: 1-14.

Isah, H., Sagagi, Y.M. and Bako, A. (2019). A Modified Boost-Boost High Gain DC-DC Converter for Photovoltaic ( PV ) Based OffGrid Applications. Nigerian Journal of Basic and Applied Science, 27(2): 70-75.

Hossain, M. Z., \& Rahim, N. A. (2018). Recent progress and development on power DCDC converter topology, control, design and applications: A review. Renewable and Sustainable Energy Reviews, 81: 205-230.

Imam A.M., Kunya A.B., and S. Y. M. (2019). Single Input Multiple Output ( SIMO ) Flyback DC - DC Converter for Off-grid Photovoltaic Applications. Savanna Journal of Basic and Applied Sciences, 1(2): 239247.

Isah, H., Sagagi, Y. M., \& Tampul, H. M. (2020). A Conventional Double Boost Converter with Voltage Multiplier Cell for Photovoltaic ( PV ) Applications. Savanna Journal of Basic and Applied Sciences, 2(1), 103-108. Jiang, J., Su, Y., Kuo, K., Wang, C., Liao, M., Wang, J., ... Shieh, J. (2016). On a hybrid MPPT control scheme to improve energy harvesting performance of traditional twostage inverters used in photovoltaic systems, Renewable and sustainable energy reviews, 98: 1-15.

Kumar, M., Ashirvad, M., \& Babu, Y. N. (2017). An integrated Boost-Sepic- Ćuk DC-DC converter with high voltage The BoostSepic- 15th International Ćuk An integrated converter with high voltage ratio and reduced input current ripple . ratio and 


\section{Nigerian Journal of Basic and Applied Science (June, 2021), 29(1): 55-62}

reduced input current ripple. Assessing the feasibility. In Energy Procedia, 117:984990).

Kuo, Y. C., Huang, Y. M., \& Liu, L. J. (2015). Integrated circuit and system design for renewable energy inverters. International Journal of Electrical Power and Energy Systems, 64:50-57.

Lai, C., Cheng Y., Teh, J. and L. Y.-C. (2017). A New Combined Boost Converter with Improved Voltage Gain as a BatteryPowered Front-End Interface for Automotive Audio Amplifiers, 20: 11081128.

Navamani, J. D., Vijayakumar, K., \& Jegatheesan, R. (2016). Non-isolated high gain DC-DC converter by quadratic boost converter and voltage multiplier cell. Ain Shams Engineering Journal, 22: 731-739.

Oulad-abbou, D., Doubabi, S., \& Rachid, A. (2019). Power switch failures tolerance of a photovoltaic fed three-level boost DC- DC converter. Microelectronics Reliability, 92: 87-95.

Öztürk, S., Poşpoş, P., Utalay, V., Koç, A., Ermiş, M., \& Çadırcl, I. (2018). Operating principles and practical design aspects of all SiC DC / AC / DC converter for MPPT in grid-connected PV supplies. Solar Energy, 176: 380-394.
Pires, V. F., Foito, D., Baptista, F. R. B., \& Silva, J. F. (2016). A photovoltaic generator system with a DC / DC converter based Cuk topology on an integrated Boost-Cuk connsverter. Solar Energy, 136: 1-9.

Rashid, M.H., (2001). Power Electronics. Academic Press Series in Engineering. ( $\mathrm{R}$. M. H., Ed.).

Sabzali, A. J., Ismail, E. H., \& Behbehani, H. M. (2014). High voltage step-up integrated double Boost-Sepic DC-DC converter for fuel-cell and photovoltaic applications. Renewable Energy, 97:1-10.

Saravanan, S., \& Ramesh Babu, N. (2017). Analysis and implementation of high stepup DC-DC converter for PV based grid application. Applied Energy, 190: 64-72.

Taghvaee, M. H., Radzi, M. A. M., Moosavain, S. M., Hizam, H., \& Marhaban, M. H. (2013). A current and future study on non-isolated DC - DC converters for photovoltaic applications. Renewable and Sustainable Energy Reviews, 17: 216-227.

Tewari, N., \& Sreedevi, V. T. (2018). A novel single switch dc-dc converter with high voltage gain capability for solar PV based power generation systems. Solar Energy, 17: 466-477. 